$\xi=-1$

\title{
Cellular Automaton based Fire Spreading Simulation in Closed Area: Clogging Region Detection
}

\author{
Najihah Ibrahim ${ }^{1}$, Fadratul Hafinaz Hassan ${ }^{2 *}$, Nor Muzlifah Mahyuddin ${ }^{3}$, Noorhazlinda Abd Rahman ${ }^{4}$ \\ ${ }^{1}$ School of Computer Science, Universiti Sains Malaysia, Malaysia \\ ${ }^{2}$ School of Computer Science, Universiti Sains Malaysia, Malaysia \\ ${ }^{3}$ School of Electrical and Electronic Engineering, Universiti Sains Malaysia, Malaysia \\ ${ }^{4}$ School of Civil Engineering, Universiti Sains Malaysia, Malaysia \\ *Corresponding author E-mail:fadratul@usm.my
}

\begin{abstract}
Fire spreading is one of the visualization techniques used for re-enacting or envisions the fire incidents for conducting the post-incidents' responses and analysing the incidents for post-mortem purposes. There are several current researches on the fire spreading incidents that involve the construction of fire spreading simulation which has focusing on the fire development, smoke control, the prediction of temperature distribution during the fire spreading, emergency response's plans and post-fire damage assessment. However, there are more features need to be explored in the fire spreading simulation and also the pedestrians movement of the affected incident's area for the future space design development, arrangement and structural improvement that are impactful towards human safety and also useful for the justification and prediction on the pedestrian survival rate during any panic situations. Hence, this research has focusing on the features of realistic scaling of the spatial layout and implementing the Cellular Automata (CA) approach for imitating the near-realistic pedestrian self-organizing movement and fire spreading characteristics at the microstructure level for designing the heat map of the affected area to show the clogging region in the spatial layout while constructing a reliable prediction on the pedestrian survival rate. This clogging region mapping will be useful for finding the existing issues that lead towards high casualties. Based on the experiments and observations, the heat map of the affected area showed the heavy congestions happened specifically near to the ingress/ egress points and narrow pathways that had affected the pedestrian flow rate and caused the $75 \%$ of the 352 pedestrians in the spatial layout to burn and die during the fire simulation by unintentionally taking an extra of 43.85 seconds more than the total fire spreading time (13.42 seconds) to evacuate from the closed area building.
\end{abstract}

Keywords: Crowd Management; Fire Spreading Simulation; Pedestrian Movement Simulation; Microscopic Movement; Cellular Automata; Clogging Region Detection

\section{Introduction}

Nowadays, there are a lot of fatal incidents happened for both natural disaster and man-made disaster. The incidents such as tsunamis, floods, hurricanes, volcanic eruptions, blizzards, wildfires, tornadoes, bombing, stampede, and etc. are able to affect the human safety and able to cause a huge calamity that lead towards high casualties [1-4]. During such incidents, the crowd will seek for a safe place for protection as for the higher land or properties during tsunamis and floods, seek for open space out of the building or affected spots during wildfires and bombing, and many more quick live saving responses as the emergency action plan. There are some well-known incidents such as huge earthquake and tsunami in Tohoku, Japan in 2011 that had caused the crowd to evacuate to the higher land, there are also big flood in Malaysia in 2014 that had caused the stranded of the crowd on the higher properties in finding the higher places to evacuate, the mass assembly of the pilgrims in Mina, Mecca in 2015 during Hajj season that had caused the stampede and the large fire in the religious school building in Malaysia in 2017 that had caused the total death of 23 person.
However, based on the incidents, the large impact of the calamities towards the casualties of the crowd can be happen when involving the closed area building structures as the accessible space by the pedestrians as the crowd. The closed area space is limited in size and only accessible via the ingress/ egress points that play a great deal as the gateways. While moving and changing the directions in the closed area, the pedestrians will always alert with the surrounding's changes and instantaneously response based on the current situation. During incidents, the pedestrians will experience the changes in the movement behaviour and direction as the situation had changed from normal situation to panic situation, as the emergency action plan.

Based on several researches, during normal situation, the pedestrian will walk with normal walking pace, influencing by the selfinterest, economy, culture and etc. with the speed approximately $1.0 \mathrm{~ms}^{-1}$, whereas, during panic situation, the pedestrian walking pace will be increased to almost approximately $5.0 \mathrm{~ms}^{-1}$, influenced by the emergency action on finding the right direction and survival instinct to save their life [5-8]. The sudden changes of the pedestrian movement behaviour during panic situation will cause an abrupt impact as the pedestrian will make a fast and full of force movements. This chaos situation is able to promote a high physical collision between the pedestrians and other entities such as the 
obstacles, wall and etc. that restrain the pedestrian from easily evacuating to the open space outside the building. This high physical collision will cause the high density of the pedestrian movement flow in the closed area and will cause the clogging region to happen especially near the ingress/ egress points or at the narrow pathways that will decrease the velocity density of the pedestrian's movement. This clogging region will cause a high impact on the casualties of the crowd that may lead towards the stampede incident especially when the pedestrian starts to startle, rushing, shoving and pushing at a narrow space within a dense crowd to find the safe place.

Besides triggering the stampede incidents, the clogging region will be the death trapped for the pedestrians especially when the explosion and fire combustion happened. The incidents that had happened in the past such as; 1) The fire spreading at The Station nightclub in Rhode Island in 2003 that had killed 100 people and injured 230 people in total due to the rapid growth of fire that has blocked the egress and entrapped the pedestrians inside the building, 2) The fire incidents at the Valley Parade stadium at the city of Bradford in UK in 1985 that had killed 56 people and injured 300 people, and 3) The tear gas explosion during riot control such as at the overcrowded Ellis Park stadium at Johannesburg, South Africa in 2001 that at least killed 43 people and injured 155 people when the crowd trying to get out from the stadium forcefully due to the tear gas and had caused a huge stampede near to the egress points [9-12]. Hence, the researchers are searching and reviewing the suitable methods to detect, predict and overcome this crowd management issue as the implication for the future incidents or for the controlling actions to reduce the casualties or as the principle guidance for the structural design, arrangement and crowd movement supervision $[2,13-16]$.

Generally, for practical experiments execution, the researches that involving the case scenario such as stampede, fire combustion, explosion and many more, will able to cause harm to human or environment while violating the ethic issue on the code of conduct. Hence, the related researches that involved with the case scenario will have high dependencies on the Artificial Intelligent (AI) by constructing the almost real simulation to re-enact or to visualize the expected situation or incidents that are about to happen in the future for more exact representation and enlightenment in the post-incident responses, structural design planning and crowd control. The demands on the exact characteristic's representation for each element (components as a building block) of a simulation are increasing due to the advancement and multidisciplinary approaches in AI researches that are able to contribute towards the crowd's well-being. The simulation for disaster's incident is really important for the prediction analysis of the pedestrian survival rate for more precise prediction [17]. Furthermore, for another advance insight, the incident's simulation is able to help the architect and interior designer to design a feasible structural and space arrangement for more crowd management friendly and ease the pedestrians to evacuate if any panic incident happens $[8,18,19]$.

Hence, this research is proposing the cellular automaton model as the building characteristic for each element in the simulation to embody the Cellular Automata (CA) approach in constructing the fire spreading simulation for further prediction on the pedestrian survival rate and detection on the pedestrians' flow rate to identify the clogging region for justifying the pedestrian entrapment during fire incident that lead towards major casualties.

\section{Cellular Automata approach: Near realistic of entities' characteristics}

During panic situation, the pedestrians will experience the sudden changes in behaviour and rapidly changing their movement directions for saving their life and avoiding any physical collision that may cause harm and injury. This chaos and unmanageable response happened due to the semi-conscious reaction of the pedestrians while executing the under pressure decision-making that display the self-organization behaviour. During the fire spreading incident, every pedestrian will keep on looking for the nearest egress point while avoiding the obstacles and other pedestrians including the hotspots such as fire, bomb and any threatening entities. The threatening entity such as fire is the most frightening existence in the layout that able to create chaos. The fire element has superior characteristics that are able to burn every obstacle from every angle. However, the fire ignition and combustion point determination has caused the fire element to be more difficult to simulate and will influence the accuracy of the simulation and the prediction analysis [13]. Hence, to design the near-realistic of the entities' characteristics, this research has introduced the Cellular Automata (CA) approach and interpreting the pedestrians' selforganization and the fire spreading behaviour as the microscopic movement of the entities for achieving the right characteristic for each time step in the simulation.

$\mathrm{CA}$ is the microstructure modelling that is able to represent the microscopic movement of a pedestrian by identifying the finite number of states within the finite number of dimension as the neighbouring cells. The CA's microstructure resemblance towards the microscopic pedestrian movement and also the fire spreading has been adapted by this research to design the near-realistic simulation. The microstructure state will always changing based on the defined relative of the element and remain within the homogeneity composition indicate by the asynchronous state of the heterogeneity composition of the neighbouring cells.

\subsection{Fire spreading simulation}

The incident of fire spreading was influenced by the combustion processes that involved the ignition process of absorbing the heat to reach the burning point for stimulating the heat and light release for further combustion and heat spreading. The fire combustion will be influenced by the presence of the oxygen molecules (the surrounding air) as the fuel for the fire to spread and growth.

In this research, the movement of the fire spreading fuelled by the oxygen molecules has been represented by the CA approach to imitate the near-realistic fire's microstructure modelling by spreading the fire element to every neighbouring cell. The neighbouring cells of fire element will be considered as burned in the next time step. However, there are some fire resistance's substances that are able to elongate the ignition time and create a time interval between the fire entities with the neighbouring cells. Based on the previous research, the closed area fire will be able to ignite and start to burn the materials in the standard condition within approximately $\approx 3-4$ seconds [20]. Hence, this research has simulate the cellular automaton based fire spreading simulation based on the characteristic shown in Fig. 1 and based on the standard materials' burning time in closed area layout previously defined by [20].

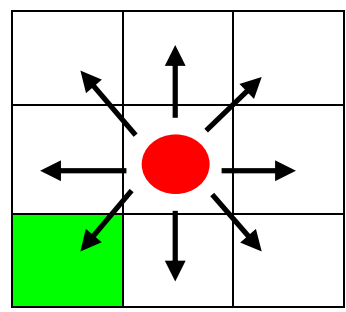

Note- The red cell colour is fire, the black colour cells are pedestrians and the green colour cell is the obstacles (The fire will be able to invaded the pedestrian and obstacles cells).

Fig. 1: Fire spreading based on the CA-Moore Neighbourhood Movement direction approach on the 2-dimensional neighbouring cells. 
Based on Fig. 1, the fire element was represented by CA approach and was enhanced with the Moore Neighbourhood direction approach to represent the widespread of the fire spreading by changing the microstructure state of the fire element with the heterogeneity and homogeneity compositions of the neighbouring cells. The basic superior rules of the fire spreading will be applied for every state for finite number of neighbouring cells.

1. At each time step, all of the neighbouring cells can be occupied by fire entity.

2. For every occupied cell that consist of obstacles and pedestrians, the fire with experience some resistance that may reach the ignition time approximately $\approx 3-4$ seconds.

3. For every occupied cell that is the floor area, the fire with experience some resistance that may reach the ignition time approximately $\approx 1$ seconds.

4. The fire must be spread and invade every cells with obstacles (pedestrian, furniture, walls and etc.) and the empty cells.

\subsection{Pedestrian movement simulation}

Pedestrian is the unique entity that will observe several probabilities on making the neighbouring movement based on the behavioural reflection of the surrounding environment (neighbouring microstructures). There are some defined and undefined relative of the characteristics display by the pedestrians especially during panic situation. Every pedestrian will relatively trying to find the nearest exit for evacuating and saving their life while relatively undefined by changing the route selection, that influenced by the neighbour cell's entities. This unique microstructure state changes will be able to represent the human intelligent, under pressure decision-making, human eyes vision and self-organization by adapting the CA approach for representing the near-realistic pedestrian's microscopic movement. Fig. 2 shows the cellular automaton based pedestrian movement simulation for every state.

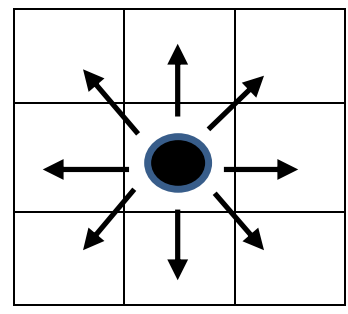

Note- The black color is the pedestrians

Fig. 2: Pedestrian movement based on the CA-Moore Neighbourhood Movement direction approach on the 2-dimensional neighbouring cells.

Based on Fig. 2, the CA approach for pedestrian movement representation has been enhanced with the Moore Neighbourhood direction approach to represent the changes of the microstructure state of the pedestrian based on the homogeneity and heterogeneity composition of the neighbouring cells. This research has introduced the optimal Moore Neighbourhood approach for imitating the near-realistic human intelligent in choosing the nearest path towards the egress point for each time step. The basic CA rules for the pedestrian movement will be applied for every state for finite number of neighbouring cells.

1. At each time step, a cell only can be occupied by a pedestrian.

2. Every pedestrian must always move for every time step based on the condition given by the neighbouring cells except for several conditions such as surrounded by the obstacles, fire or other pedestrians.

3. Every pedestrian will always avoid any physical collision with the obstacles, fire, walls and other pedestrians.

4. Every pedestrian will always find the nearest exit for evacuation process and influenced by the neighbouring cells' entities.

5. The wall and obstacles will remain permanent at the same spot and will burn during the fire spreading.

\section{Spatial layout design configuration}

Closed area building is the place that responsible for a lot of important events and also important for the daily basis operations; such as the stadium, auditorium, class room, office space, lecture hall, cinema and etc. These indoor spaces will be able to accommodate a large number of crowds and consist of several furnishing materials such as chairs, tables and etc. This research is based on the real structural design; the lecture hall of Universiti Sains Malaysia (USM) as the target spatial layout to simulate the nearrealistic pedestrian movement and fire spreading for analysing the pedestrians' evacuation process and fire spreading process. Fig. 3(a) shows the design of the closed area lecture hall with 432 square meters $(\mathrm{s} / \mathrm{m})$ and scaled into $40 \times 30$ grid cells (the wall will not be included based on the actual size lecture hall's blueprint) and Fig. 3(b) shows the fire spreading simulation in the spatial layout.
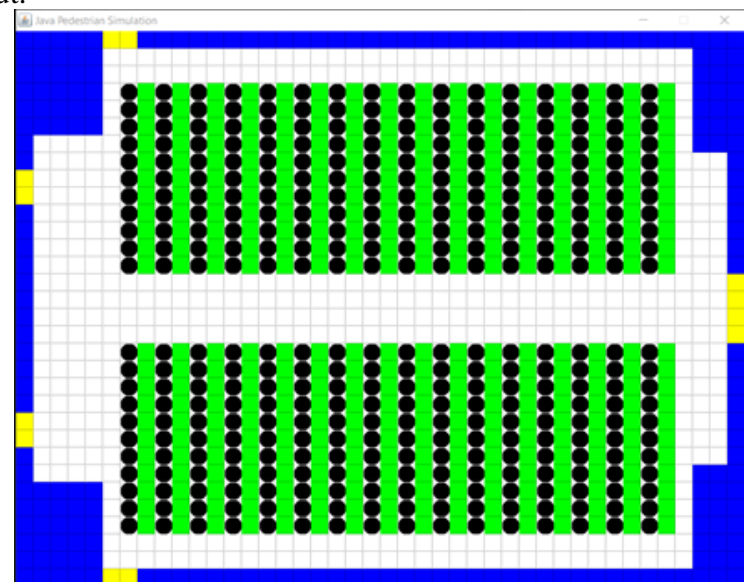

Fig. 3 (a)

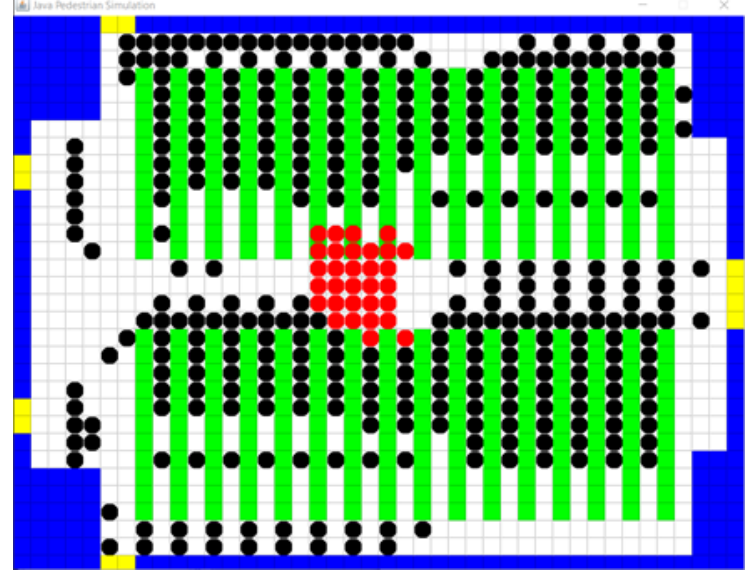

Fig. 3 (b)

Note- The black color cells are the pedestrians, the red color cells are the fire, the green color cells are the chair (obstacles), the white color cells are floor, the blue color cells are walls, and the yellow color cells are the door.

Fig. 3: (a) The Configuration of the spatial layout based on the actual size, (b) The fire simulation in the spatial layout. 
Based on Fig. 3 (a), the grid cells was designed with the size of $0.6 \mathrm{~m}$ for each grid cell for complimenting the standard human size, the door size and the lecture hall's chair size [21, 22]. In Fig. $3(\mathrm{~b})$, the fire was ignite at the cell $\mathrm{x}=20$ and $\mathrm{y}=15$ in the middle of the lecture hall.

\section{Framework: The pedestrian movement and fire spreading simulation}

This research was carried out to analyse the pedestrian flow rate for detecting the clogging region while discussing on the future prediction on the pedestrian survival rate. Hence, to construct the overall entities and represent the characteristics for each microstructure in the spatial layout based on the near-realistic elements for each time step, this research has simulate the pedestrian movement and fire spreading based on the conceptual research framework shown in Fig. 4.

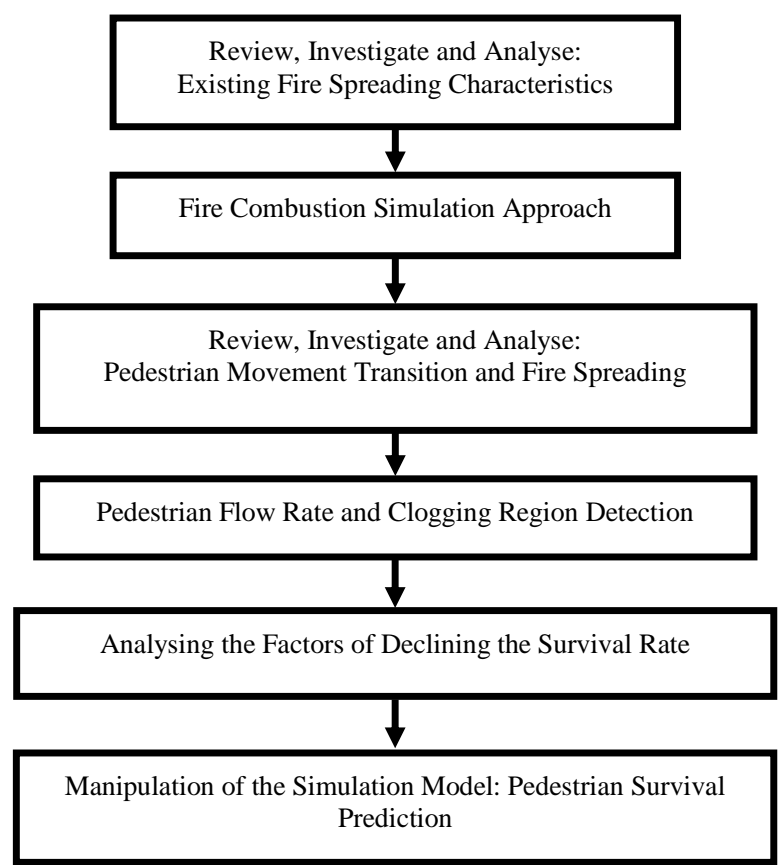

Fig. 4: The conceptual framework for constructing the near-realistic pedestrian movement and fire-spreading simulation and observation manipulation for further critical analysis.

Based on Fig. 4, the basic fire elements have been identified for designing the near-realistic fire ignition and combustion. The identified characteristics has been deployed to simulate the fire spreading while implementing the current pedestrian movement transition simulation that has been discovered in the previous research by implementing the CA model approach to mimics the characteristic for each movement state at the microstructure level $[19,23,24]$. The result of the CA based simulation will be useful for determining the pedestrian flow rate near to the egress point while detecting the clogging region of the spatial layout. The flow rate calculation for each of the egress point was adapted from the fluid flow rate measurement for liquid volume flow rate in the pipe shown in Equation 1:

$$
\text { Pedestrian Flow Rate for Each Exit }=P / t
$$

where $P$ is the number of pedestrians passes by each of the egress point and $t$ is the time (seconds) for all of the pedestrians to manage to evacuate from the spatial layout. The result of the flow rate will be able to assist on the detection of the heavy usage of egress by the pedestrians to evacuate. The result of this research experiments will be usable to be analysed critically for further prediction on the pedestrian survival rate.

\section{Experimental setup}

This research simulation experimental setup will be based on the university lecture hall that was designed in grid cells for $40 \times 30$ cells to represent the 432 square meters $(\mathrm{s} / \mathrm{m})$ area with the ration of $0.6 \mathrm{~m}$ for each cell [21,22]. The experiments will be set based on several condition; 1) Normal situation, 2) Panic situation without fire, 3) Panic situation with fire spreading (the fire was set up at grid cell; $x-20, y-15)$ and 4) Fire spreading without the pedestrians to determine the time for overall fire spreading of the hall. The pedestrian movement speed during normal situation will be set as $1.0 \mathrm{~ms}^{-1}$ and $5 \mathrm{~ms}^{-1}$ for panic situation $[6,7,25]$. The time (seconds) for the total number of burned cells will be recorded. The number of pedestrians involve in this simulation will be set for 352 pedestrians to represent the best case of the daily full attended lecture hall. The number of pedestrians that are able to evacuate from the incident area and the number of death will be determined. The evacuation time (seconds) of the last pedestrian(s) that is/are successfully evacuate from the spatial layout will be determined to represent the overall time taken by the pedestrian to evacuate. The result will be evaluated for analysing the issue of the unfortunate pedestrians that were trapped inside the closed area and the need of extra times for the evacuation process during fire spreading incident.

\section{Result and analysis}

The experiments for this research objective were conducted for investigating and analysing the pedestrian movement and fire spreading simulation for the closed area building, specifically the university lecture hall. The simulation were executed by employing the Cellular Automata (CA) approach with the enhancement on the optimal Moore Neighbourhood direction movement in representing the microstructure characteristics for each state with various probability on the selected spatial layout. Table 1 show the result based on the experiment setup.

Based on Table 1, the lecture hall was setup with the full number of pedestrians (students) that is 352 pedestrians. During normal situation, with the walking speed of $1.0 \mathrm{~ms}^{-1}$, the 352 pedestrians took 68.41 seconds to evacuate and clear the space. The time taken for the normal situation can be consider as the best case of the pedestrian walking leisurely out from the closed area, given that the pedestrian have the intention for finding the nearest exit.

Table 1: Experiment result of the simulation

\begin{tabular}{|c|c|c|c|c|c|c|}
\hline \multicolumn{1}{|c|}{$\begin{array}{c}\text { Simulation } \\
\text { Condition }\end{array}$} & $\begin{array}{c}\text { Number of } \\
\text { Burned } \\
\text { Cells (Grid } \\
\text { Cells) }\end{array}$ & $\begin{array}{c}\text { Time (s) } \\
\text { for Total } \\
\text { Burned }\end{array}$ & $\begin{array}{c}\text { Total Number of } \\
\text { Pedestrian }\end{array}$ & Survive & Dead & $\begin{array}{c}\text { Time (s) to } \\
\text { Evacuate } \\
\text { (Last Alive } \\
\text { Pedestrian) }\end{array}$ \\
\hline $\begin{array}{c}\text { Normal } \\
\text { Situation }\end{array}$ & NA & NA & 352 & 352 & NA & 68.41 \\
\hline $\begin{array}{c}\text { Panic Situation } \\
\text { (Without Fire) }\end{array}$ & NA & NA & 352 & 352 & NA & 57.27 \\
\hline $\begin{array}{c}\text { Panic Situation } \\
\text { (During Fire } \\
\text { Spreading) }\end{array}$ & 1344 & 13.42 & 352 & 89 & 263 & 13.41 \\
\hline
\end{tabular}




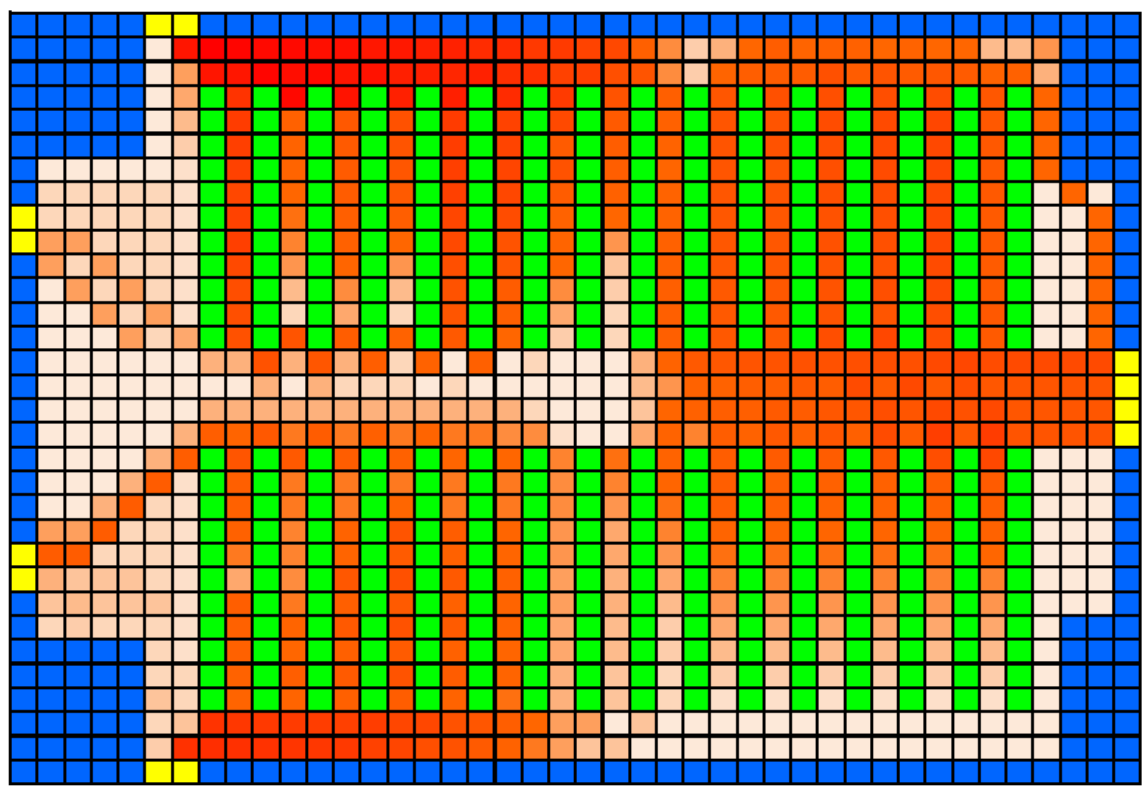

Fig 5: The heat map of the clogging region for the closed area building (E1 = Doorways 1 with two doors, $E 2=\mathrm{Doorways} 2$ with two doors,

E3 = Doorways 3 with two doors, E4 = Doorways 4 with two doors and E5 = Doorways 5 with four doors)

During usual panic situation without involving any fire spreading incident, the 352 pedestrians took 57.27 seconds to totally evacuate from the space. During the panic movement, the pedestrian will show the sudden and forceful movement that will able to create the situation "freezing in hot" that will result the bottleneck issue especially at the narrow pathways and at the egress points. This "freezing in hot" phenomenon happened due to the clogging issue and usually took place at the ingress/ egress points of the layout. Table 2 shows the flow rate of the 352 pedestrians for each of the ingress/ egress point for the closed area lecture hall (Refer Fig.5 for door's number) as for normal and panic situation to highlight the obstructing of the doorways.

Table 2: Pedestrian flow rate for each door of the doorways (E1, E2, E3, $\mathrm{E} 4=$ One of the two doors, E5 = One of the four doors) for both normal situation and panic situation for 352 pedestrians

\begin{tabular}{|l|c|c|c|c|c|}
\cline { 2 - 6 } \multicolumn{1}{c|}{} & E1 & E2 & E3 & E4 & E5 \\
\hline $\begin{array}{l}\text { Normal } \\
\text { Situation }\end{array}$ & 0.073 & 0.154 & 0.746 & 0.512 & 0.545 \\
\hline $\begin{array}{l}\text { Panic Situa- } \\
\text { tion }\end{array}$ & 0.088 & 0.184 & 0.891 & 0.611 & 0.651 \\
\hline
\end{tabular}

Based on Table 2, the pedestrians flow rate has shown that the ingress/ egress number 3 (E5) and number 4 (E4) had experienced the high flow which represent the heavy crowd near to the doorways with low velocity that formed the clogging region, followed by the other doorways and the ingress/ egress number 5 (E5) and number 2 (E2). The ingress/ egress number 1 (E1) shown the lowest used by the pedestrian for evacuation process. Thus, this flow rate result from Table 2 was analysed and the further visualization was discovered to show the clogging region. Figure 5 shows the heat map of the spatial layout to show the pedestrians' movement pattern and clogging region.

Based on Figure 5, the heat map was designed with colour range from light brown to red to show the high clogging region space and the free space without any clog. The red colour regions has shown there are clogging happened that caused high physical collision and able to trigger a stampede incident. The light brown colour regions are the regions that being less used by the pedestrians due to the long distance from the egress point. Based on the Figure 5, the heat map had support the result from Table 2 that has shown the clogging region near to the ingress/ egress, especially for doorways E3, E4 and E5. However, from the observation, the clogging regions were formed due to the obstacles (chairs) arrangement near to the doorways that had established a pattern for the pedestrian movement during evacuating from the spatial layout. The pedestrian have had to queue and engage with heavy physical collision near the doorways and the narrow pathways in between the chairs. Hence due to this situation, the result from Table 1 was obtained.

Based on the result from Table 1, the fire can be spread to the whole layout (without the pedestrians) by burning all of the 1344 number of grid cells with the burning time 13.42 seconds. The calculation of the fire spreading was based on the standard combustion proposed by [20]. The 13.42 seconds will be the benchmark for the further prediction of the pedestrian survival rate because the pedestrian who are able to evacuate $<13.42$ seconds will be consider as the survivor of the incidents. Based on the first result of the evacuation without fire spreading, the pedestrian spent 57.27 seconds to evacuate, which is almost 5 times slower than the fire spreading time. However, during the spreading and combustion process, human also become one of the fire resistant that required $\approx 3-4$ seconds to be ignited, burned and spread the fire to the neighbouring cells. Hence, during the present of the 352 pedestrians in the spatial layout, the fire spreading incident took 13.41 seconds to burn the 263 pedestrians while only 89 pedestrians are able to evacuate to the safe place. Based on this simulation result, less than half of the pedestrians in the spatial layout were declared as dead due to the entrapment in the closed building. This issue was highly contributed by the large clogging region in front of the ingress/ egress points and in between the narrow path of the chairs. Based on Figure 5, the pedestrian were clogged and pushed towards the wall while waiting for their turn to evacuate through the small exit point (refer to red colour grids near to E3, E4 and E5 doorways). During the fire spreading, while queuing to evacuate, the pedestrian will also avoiding the collision with the neighbouring cells that consist of fire and other pedestrians. Hence, due to the dead-end circumstance, 263 pedestrians were entrapped inside the closed area and were burned.

Based on the results in Table 1, Table 2 and also the heat map created from the experiment in Figure 5, the right authority can pay an extra observation by adding more egress point or enlarge the egress point for the pedestrian to evacuate on time. The number of the pedestrian loaded into the closed area also can be controlled with the implementation of the principle guidance on the lecture hall usage, especially in this research by not allowing the closed area to be filled with 352 students at one time. The design 
of the lecture hall is also must be revised for more conducive for the students (pedestrians) to move and to evacuate especially during panic situation.

\section{Conclusion}

Cellular Automata (CA) is the suitable model approach to mimics the near-realistic situations in constructing a simulation to represent the microstructure level of the pedestrian movement and fire spreading in a closed area building. For every time step for each entity, the CA approach will be able to highlight the real reflex actions and elements that influence a pedestrian's decision in moving and the spreading of the fire. The fire spreading time consumption for each state such as the time to burn the obstacles and human must be $\approx 3-4$ seconds to imitate the standard closed area of fire ignition and combustion. During the simulation of the pedestrian movement and the fire spreading, the main issue was identified, that the clogging region in front of the ingress/ egress and at the narrow pathways had caused the high casualties of the pedestrians. There are 43.86 seconds of time wasted by the 263 dead pedestrians in the layout due to the congestion near to the egress point, massive queuing for evacuation and due to the high physical collision avoidance caused by the entrapment. The casualties of the pedestrians has been predicted to be less than the result of this research if the right authorities will able take an extra precautions on re-structuring the lecture hall (closed area) for providing more spaces near to the ingress/ egress points, enlarging the pathways in between the chairs and adding more doorways to increase the pedestrian's movement access. Hence, for the future findings, this research aims to design the feasible interior of the closed area for reducing the clogging region during panic situation and also reducing the number of casualties of the pedestrians during evacuation process.

\section{Acknowledgement}

Research experiment reported here is pursued under the Bridging Grant by Universiti Sains Malaysia for "Pedestrian Simulation Model for Clogging Detection and Survival Prediction in a Fire Spreading Situation" [304.PKOMP.6316019], Research University Grant (RUI) by Universiti Sains Malaysia for "Bio-Inspired Optimization Algorithm for Spatial Layout Design of Cul-de-sac Area using Microscopic Pedestrian Movement in a Panic Situation" [1001.PKOMP.8014073] and Fundamental Research Grant Scheme (FRGS) by Ministry of Education Malaysia for "Enhancing Genetic Algorithm for Spatial Layout Design Optimization with Pedestrian Simulation in a Panic Situation" [203.PKOMP.6711534]. The preliminary study of this research is supported under the Short Term Grant Scheme by Universiti Sains Malaysia for "Pedestrian Simulator and Heuristic Search Methods for Spatial Layout Design" [304.PKOMP.6313169]

\section{References}

[1] Four in a Family Killed in Fire, in The Star Online. 2017, Star Media Group Berhad (ROC 10894D).

[2] Henderson, B. and C. Graham, Dubai Skyscraper Fire: Torch Tower Residents Wake to Screams as Flames Engulf 79-Storey Building, in The Telegraph. 2017, Telegraph Media Group Limited 2017: Unted Kingdom.

[3] Jay, B.N., Tahfiz did not have fire exit; bodies found piled on top of each other, in New Straits Times. 2017, New Straits Times Press (M) Berhad: Malaysia.

[4] Zong, X. and Y. Jiang. Pedestrian-vehicle mixed evacuation model based on multi-particle swarm optimization. in 2016 11th International Conference on Computer Science \& Education (ICCSE). 2016.

[5] Wineman, J.D. and J. Peponis, Constructing Spatial Meaning: Spatial Affordances in Museum Design. Environment and Behavior, 2010. 42(1): p. 86-109.
[6] Helbing, D. and A. Johansson, Pedestrian, Crowd, and Evacuation Dynamics, in Encyclopedia of Complexity and Systems Science, R.A. Meyers, Editor. 2009, Springer New York: New York, NY. p. $1-28$.

[7] Helbing, D., et al., Simulation of pedestrian crowds in normal and evacuation situations. Pedestrian and evacuation dynamics, 2002. 21(2): p. 21-58.

[8] Pluchino, A., et al., Agent-Based Simulation of Pedestrian Behaviour in Closed Spaces: A Museum Case Study. Journal of Artificial Societies and Social Simulation, 2014. 17(1): p. 16.

[9] Football stadium disasters, in The Telegraph. 2001, Telegraph Media Group: United Kingdom.

[10] Friberg, M. and M. Hjelm, Mass evacuation-human behavior and crowd dynamics-What do we know? Law Review, 2014. 50(3): p. 747-823.

[11] Mahoney, E.J., et al., Lessons learned from a nightclub fire: institutional disaster preparedness. Journal of Trauma and Acute Care Surgery, 2005. 58(3): p. 487-491.

[12] Lu, X., et al., Impacts of Anxiety in Building Fire and Smoke Evacuation: Modeling and Validation. IEEE Robotics and Automation Letters, 2017. 2(1): p. 255-260.

[13] Yan, Z., X. Han, and M. Li. Accurate Assessment of RSET for Building Fire Based on Engineering Calculation and Numerical Simulation. in MATEC Web of Conferences. 2016. EDP Sciences.

[14] Sime, J.D., Crowd psychology and engineering. Safety Science, 1995. 21(1): p. 1-14

[15] Hassan, F.H. Using microscopic pedestrian simulation statistics to find clogging regions. in 2016 SAI Computing Conference (SAI). 2016.

[16] Proulx, G., High-rise evacuation: a questionable concept, in Proceedings of the 2nd International Symposium on Human Behaviour in Fire. 2001, Interscience Communication Ltd: Boston, MA, USA.

[17] Alidmat, O.K.A., F.H. Hassan, and A.T. Khader. Cellular automata model for pedestrian evacuation in fire spreading conditions. in Proceedings of the 5th International Conference on Computing and Informatics, ICOCI 2015. 2015. Istanbul, Turkey: Universiti Utara Malaysia.

[18] Hassan, F.H. and A. Tucker, Automatic Layout Design Solution, in Advances in Intelligent Data Analysis X: 10th International Symposium, IDA 2011, Porto, Portugal, October 29-31, 2011. Proceedings, J. Gama, E. Bradley, and J. Hollmén, Editors. 2011, Springer Berlin Heidelberg: Berlin, Heidelberg. p. 198-209.

[19] Ibrahim, N., F.H. Hassan, and S.A. Zakaria. Incorporating Cellular Automaton based Microscopic Pedestrian Simulation and Genetic Algorithm for Spatial Layout Design Optimization. 2019. Singapore: Springer Singapore.

[20] Abrahams, J. and P. Stollard, Fire from first principles: a design guide to building fire safety. 2003: Routledge.

[21] Liu, R., D. Jiang, and L. Shi, Agent-based simulation of alternative classroom evacuation scenarios. Frontiers of Architectural Research, 2016. 5(1): p. 111-125.

[22] Papinigis, V., E. Geda, and K. Lukošius, Design of people evacuation from rooms and buildings. Journal of Civil Engineering and Management, 2010. 16(1): p. 131-139.

[23] Najihah Ibrahim, Nur Shazreen Nabiha Mat Tan Salleh, and F.H. Hassan. Cellular Automaton Based Simulation in Panic and Normal Situations: A Case Study on the University Lecture Hall. in Future Technologies Conference (FTC 2017). 2017. Vancouver, Canada: SAI Conferences.

[24] Ibrahim, N., et al., Features of Microscopic Horizontal Transition of Cellular Automaton based Pedestrian Movement in Normal and Panic Situation. Journal of Telecommunication, Electronic and Computer Engineering (JTEC), 2017. 9(2-12): p. 163-169.

[25] Helbing, D., I. Farkas, and T. Vicsek, Simulating dynamical features of escape panic. Nature, 2000. 407(6803): p. 487-490. 